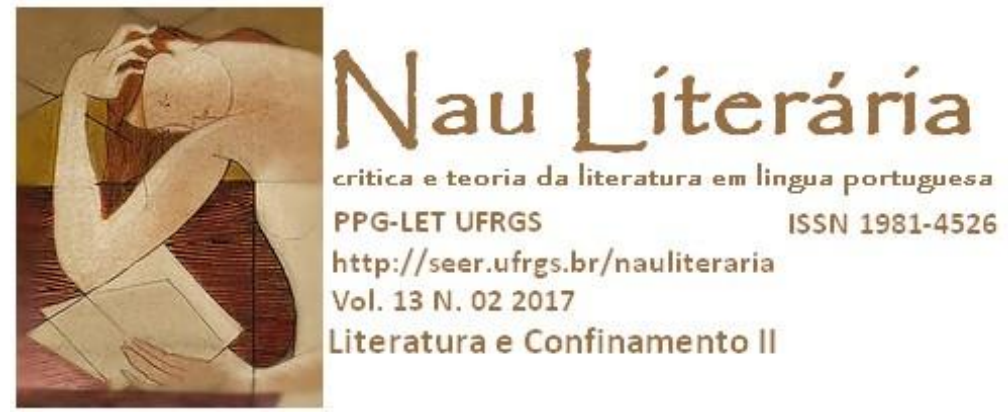

\title{
“Minha linguagem não é gaúcha": Josué Guimarães e suas relações de regionalidade
}

\author{
João Cláudio Arendt \\ Márcio Miranda Alves
}

\begin{abstract}
Resumo: Este artigo analisa as especificidades da narrativa ficcional de Josué Guimarães pelo viés da regionalidade. Partindo das declarações do escritor de que não se considerava regionalista, busca-se mostrar como os elementos regionais presentes em um obra costumam ser interpretados de forma equivocada, tanto pelos autores quanto pela crítica, cujos julgamentos implicam quase sempre juízos de valor. A solução encontrada para explicar a presença dos aspectos regionais na produção ficcional brasileira parte, via de regra, pela oposição entre local e universal, considerando apenas a linguagem empregada e não o posicionamento do autor diante do espaço sociocultural representado. Assim, a partir das ideias de Barcia (2004) e Stüben (2013), procura-se definir a obra regionalista para, em seguida, demonstrar que a narrativa de Josué Guimarães, particularmente $A$ ferro $e$ fogo, pode ser investigada a partir de suas regionalidades internas, sem que os seus elementos regionais indiquem manifestações regionalistas.
\end{abstract}

Palavras-chave: regionalidade; regionalismo; Josué Guimarães; A ferro e fogo.

\begin{abstract}
This paper analyzes the specificities of fictional narrative written by Josué Guimarães through the bias of regionality. Based on the writer's statements in which he did not consider himself a regionalist, it seeks to show how regional elements present in a work are often misinterpreted by authors and critics, whose view almost always involves judgments of value. The solution found to explain the presence of regional aspects in Brazilian fiction production is usually based on the opposition between local and universal, considering only the language used and not the position of the author in the socio-cultural space represented. Thus, from the ideas of Barcia (2004) and Stüben (2013), it seeks to define the regionalist work and demonstrates that the Josué Guimarães' narratives, particularly A ferro e fogo, can be investigated from its internal regionalities without indicating regionalist manifestations.
\end{abstract}

Keywords: regionality; regionalism; Josué Guimãres; A ferro e fogo.

Em entrevista a Charles Kieffer, Vera Teixeira de Aguiar e Roberto Fleck, publicada no volume 19 de Autores gaúchos, o escritor Caio Fernando Abreu, ao ser perguntado sobre sua relação com a tradição "fundamentalmente regionalista e social” do Rio Grande do Sul, respondeu que não tinha "nada a ver com isso" (1995, p. 5). Embora, na sequência, afirme admirar Erico Verissimo, essa admiração seria fruto do caráter universal e mítico da sua obra, pois o autor de $O$ tempo e o vento, nas suas palavras, "não é regionalista" (1995, p. 5). Em outros termos, Caio acredita que o caráter universal de Erico residiria no fato de que, "falando de uma árvore, ele conseguia falar de uma floresta inteira" (1995, p. 5). 
A recusa em se filiar à tradição regionalista é mais comum do que se imagina entre os autores brasileiros. O próprio Erico Verissimo, citado por Caio e tantas vezes apodado como tal, manifestou-se contrário ao vínculo de sua obra com o regionalismo em pelo menos dois momentos. O primeiro, em 1971, quando Celito de Grandi indagou se seria possível classificá-lo, até o lançamento de $O$ senhor embaixador (1965), como regionalista, e Erico asseverou:

Protesto! Nunca fui regionalista. Pelo menos nunca pretendi ser. A não ser que um sujeito que escreve sobre Paris ou Roma possa ser considerado regionalista. Claro, O tempo e o vento tem aspectos 'regionalistas', isto é, campeiros, gauchescos. O que quero dizer é que não sou regionalista como foram Simões Lopes Neto, Darcy Azambuja e Vargas Neto. (VERISSIMO, 1999, p. 84)

O segundo momento acontece em 1973, em entrevista à Rosa Freire D’Aguiar, para a revista Manchete, quando, questionado se concordava com o rótulo regionalista que lhe imputavam, respondeu: "Estou longe de ser um regionalista. Mesmo em $O$ tempo e o vento usei o mínimo de vocábulos regionais (noto que hoje em dia se escreve muito em mineiro, baiano, pernambucano)". (VERISSIMO, 1999, p. 183, grifos do autor).

Recentemente, Milton Hatoum respondeu de forma similar a uma pergunta sobre sua relação com a tradição dos autores amazonenses: "Nenhuma [relação]. Não apenas os amazonenses, como também os que escreveram sobre o Amazonas, como o Euclides da Cunha ou o próprio Ferreira de Castro. A Selva é um romance com muitos problemas, inclusive de racismo. Não gosto dessa literatura regionalista amazonense, paraense. Quero


amazônica resultaria de o regionalismo ser problemático em razão do tom preconceituoso e pitoresco. Em outra ocasião, Hatoum até acusou os estudiosos de realizarem uma leitura equivocada da sua obra: "[...] para um resenhista apressado ou de olhar turvo, um romance ambientado na Amazônia é rotulado de regionalista."”2

A lista de autores que procura escapar à pecha regionalista é extensa e deixa entrever o mal-estar que ela provoca. É provável que esse sentimento resulte do preconceito criado pela própria crítica literária, que, historicamente, apodou o regionalismo como menor e sem valor literário, ou teve que adjetivá-lo positivamente para salvaguardar alguns autores. E aqui se podem citar como exemplo alguns epítetos utilizados por Alfredo Bosi, na sua História

1 Disponível em: http://www.revistadehistoria.com.br/secao/entrevista/milton-hatoum. Acesso em: 10 nov. 2015.

2 Disponível em: http://alexandregaioto.blogspot.com.br/2011/10/entrevista-milton-hatoum.html. Acesso em: 10 nov. 2015. 
Concisa da Literatura Brasileira (1970), para caracterizar os (supostos) diferentes regionalismos brasileiros: o tenso e crítico, o de crônica ou reportagem, o menor e amante do típico e do exótico, o apegado a velhas convenções narrativas, o de valor documental, o moderno e complexo, o neorrealista, o de simples registro de costumes locais, o de opção crítica e de engajamento, o de novelística da terra, o tradicional, o de incursão na alma primitiva, o telúrico, bárbaro e primordial, o de esconjuro do pitoresco e do exotismo de epiderme, e o banal que copia as superfícies.

Em estudo sobre Guimarães Rosa e seus precursores, André Tessaro Pelinser afirma que, na História Concisa..., de Bosi, "a debilidade dos conceitos dificulta uma apropriada disposição dos autores na tradição. Afinal, enquanto anteriormente definia-se o escritor regionalista como aquele que se esquivava à problemática universal, agora Guimarães Rosa surge, en passant, enquadrado nessa classificação, a despeito de uma reflexão sobre o termo" (2015, p. 208). Sob nosso ponto de vista, além disso, a debilidade de conceitos bate em cheio na questão do valor literário e não leva em conta a função da literatura que aborda temas regionais.

Para Ligia Chiappini, à revelia da qualidade estética, o regionalismo cumpriria um papel importante na vida social, já que ele, historicamente, contestaria políticas nacionalistas estreitas e totalitárias, e aproximaria "solidariamente o leitor da cidade do homem pobre do campo, auxiliando-nos a vencer preconceitos, respeitar a diferença e alargar nossa sensibilidade ao descobrir a humanidade do outro de classe e de cultura" (1995, p. 154). Em outros termos, Chiappini acredita que nessa vertente nem tudo é tendencioso, caipora ou conservador. Da nossa parte, entendemos que o regionalismo foi e ainda pode ser porta-voz de determinados grupos sociais que se encontram à margem das representações literárias e/ou artísticas. Em alguns casos, também sem considerar o mérito da qualidade e a autonomia da literatura, o elogio da cultura regional pelo texto literário pode até ser benéfico para o grupo, se esse se encontra ameaçado por forças niveladoras e descaracterizadoras da sua identidade ou, ainda, se for preterido pelos processos culturais. Hostilizar essa tendência literária parece imprudente, porque alimenta tanto o preconceito literário (regionalismo = literatura de baixa qualidade) quanto os estereótipos culturais (região = espaço provinciano e atrasado).

Dois exemplos que podem ilustrar sobremaneira essa questão referem-se a grupos étnico-sociais regionais resultantes de fluxos imigratórios iniciados no século XIX e que, por longo tempo, tiveram porta-vozes literários puramente laudatórios e, frise-se agora, sem nenhuma expressividade artística. O primeiro grupo, da imigração alemã, obteve visibilidade 
por meio da obra literária de Josué Guimarães, com a trilogia incompleta de A ferro e fogo ${ }^{3}$, publicada em 1972 e 1975. O segundo, de imigração italiana, também obteve evidência literária apenas através da obra de José Clemente Pozenato, com sua trilogia publicada entre 1985 e $2006^{4}$. Ambos os autores integram, junto com Charles Kiefer, o que o Atlas das representações literárias de regiões brasileiras/IBGE (2006) denomina como "regionalismo cultural", em razão da representação literária da "Região das Colônias" alemã e italiana no Rio Grande do Sul.

No caso de Josué Guimarães, também é perceptível a negação do rótulo de regionalista quando afirma não ter sofrido a influência de autores gaúchos, mas de Graciliano Ramos, Jorge Amado e Machado de Assis, "além, é claro, dos grandes nomes do romance francês, dos contemporâneos norte-americanos e dos latino-americanos deste século" (GUIMARÃES, 1988, p. 6). Quanto a Erico Verissimo, Josué admite a sua influência unicamente "pela maneira profissional com que encarava o seu trabalho e pela impressionante retidão do seu caráter" (1988, p. 6). De resto, apesar de reconhecer a presença da temática regional em sua obra, Josué afirma que procura empregar "uma linguagem o mais possível nacional" (1988, p. 6).

A polarização entre linguagem regional e nacional parece ser, nesse contexto, a principal forma de distinção entre uma obra regionalista e uma obra não regionalista. Ela aparece também nas declarações de Erico Verissimo a propósito do seu O tempo e o vento, conforme já demonstramos anteriormente. Josué Guimarães afirma que sua linguagem não é gaúcha e que ele até se esforça para que não seja, procurando, dessa forma, evitar o que ele chama de "modismos gaúchos". A declaração a seguir é pertinente:

O que entendemos por regionalismo? O linguajar do gaúcho? O linguajar fechado, o linguajar de Simões Lopes Neto? É, é um tipo de regionalismo. Mas o Rio Grande tem outros regionalismos. Podemos usar uma linguagem nacional, uma linguagem encontrada em qualquer dicionário, sem modismos gaúchos, de muita qualidade. (GUIMARÃES, 1988, p. 8)

Parece-nos que, para Josué Guimarães e outros autores, o requisito principal do regionalismo reside, fundamentalmente, no uso de uma linguagem regional, fechada e cheia e modismos, e não no posicionamento do autor diante do universo sociocultural representado. $\mathrm{O}$ aspecto ideológico da representação literária fica, assim, em segundo plano, subsumido tanto pelo elemento linguístico quanto pelo enfoque temático e paisagístico, conforme se vê nesta passagem: "Não posso me considerar um escritor regional, meus temas giram em torno do

3 A ferro e fogo I - Tempo de solidão (1972) e A ferro e fogo II - Tempo de guerra (1975).

4 O quatrilho (1985), A Cocanha (2000) e A Babilônia (2006). 
homem, seus conflitos, contradições; a paisagem, quando existe, vale apenas para dar acabamento à pintura" (GUIMARÃES, 1988, p. 7).

Em razão do exposto, o autor de A ferro e fogo define tanto seu estilo (marcado por "uma certa rebeldia") quanto sua temática como latino-americanos. A perplexidade e o desejo de desvendar a natureza humana tê-lo-iam levado a temas como "o subdesenvolvimento, a miséria, o caldeamento de raças, a insegurança social e política, o caudilhismo, a passividade diante do destino, a ignorância, a doença, a crença de que ninguém muda nada, estava escrito" (GUIMARÃES, 1988, p. 7). Isso tudo, considerando ainda a sua professada inclinação para o realismo mágico da América Latina, fruto de um quadro político que obrigaria o escritor a não poder dizer "pão-pão, queijo-queijo", mas a falar em "borboletas, pássaros, gaiolas, labirintos, muros" (GUIMARÃES, 1988, p. 7).

Nesse contexto de análise, os juízos da crítica podem ser pertinentes. Therezinha Barbieri, por exemplo, afirma que Josué Guimarães conseguiu trabalhar os temas sul-riograndenses "descolados" do localismo, distinguindo-se, por exemplo, de Simões Lopes Neto, por tentar enquadrá-los diretamente na dinâmica da cultura ocidental. Em outros termos, o romancista teria evitado o esmiuçamento da matéria local com vistas a posteriormente transcendê-la: "A colonização, as guerras de fronteira, as idiossincrasias dos gaúchos são tratadas com vistas a uma recepção no registro geral". A autora ainda afirma que a ele aplicarse-ia a mesma máxima que Antonio Candido decalcou no Machado de Assis romântico: “[...] fazer "literatura universal pelo aprofundamento das questões locais"” (BARBIERI, 1997, p. 36).

Para o pesquisador Miguel Rettenmaier, coordenador do Acervo Literário José Guimarães, o autor de Camilo Mortágua teria conseguido, com o cosmopolitismo resultante do jornalismo e da política, "escrever como poucos sobre o Rio Grande do Sul e sobre o homem que aqui viveu e vive" (RETTENMAIER, 2009, p. 141). Ao mesmo tempo, sem jamais se apresentar como um autor gaúcho, ele "defendia em sua obra as forças do regionalismo, mas não prescindia da universalidade dos temas.”

A invocação do universal(ismo), quando da menção ao local(ismo) ou ao regional(ismo), constitui uma estratégia discursiva interessante na atividade crítica brasileira. De um modo geral, as definições de localismo, regionalismo e universalismo são precárias e pouco elucidativas do referente. Tomemos, primeiro, a proposição de Barbieri no que diz respeito ao "descolamento do localismo" e à proposta de Josué de se enquadrar diretamente na cultura ocidental. É difícil saber como se dá, na prática, esse processo, já que qualquer elemento cultural é, em certo sentido, local, ou seja, conecta-se a um espaço de onde ele 
emerge e sobre o qual atua. Da mesma forma, não nos parece razoável dizer que o autor dá um tratamento a tema locais "com vistas a uma recepção no registro geral", porque não se consegue alcançar o sentido da expressão "registro geral". Quanto ao depoimento de Rettenmaier, pensamos que a denominada "universalidade dos temas" de que Josué não prescindia também é nebulosa, tendo em vista que qualquer tema pode ser matéria de literatura, em qualquer ponto do planeta. Não existem, na nossa opinião, temas mais ou menos importantes, mais ou menos literários, mais ou menos "universais".

Com base nessa discussão inicial, que consideramos oportuna como introdução ao tema proposto para este ensaio, cumpre-nos dizer ainda que a literatura regionalista pode ser definida não como aquela que simplesmente se ambienta na região, mas sim como aquela que toma a região na perspectiva idealizada enquanto espaço cultural. $\mathrm{O}$ argentino Pedro Barcia elenca uma série de traços identificadores da literatura regionalista que parecem adequados ao que propomos. Uma obra regionalista, segundo o autor:

1. Se ata a una estética romántica apoyada en el color local.

2. Tiende al exhibicionismo colorista y al pintoresquismo.

3. Prefiere el descripcionismo que acaba por tragarse todo [...].

4. Predomina en ella el énfasis sentimental ponderativo.

5. Adopta el gesto desdeñoso y excludente de lo ajeno.

6. Contiene excesivas notas nostálgicas. Tono elegíaco.

7. Practica el culto al pasado. Gerontofilia y neofobia.

8. Se place en el encaracolamiento en el próprio, la cerrazón cultural. La región como valva protetora.

9. Acentúa el espíritu de campanario cultural.

10. Tiene el temor de las influencias: lo exterior es nocivo.

11. Tiende a la tipificación psicológica en la narrativa.

12. Exige una enciclopedia regional en el lector. (BARCIA, 2004, p. 41-42)

Na proposta de Barcia, vê-se claramente que uma postura laudatória, romântica, pitoresca, xenófoba, nostálgica, elegíaca, neófoba, escapista e conservadora em relação à região devem estar presentes na representação literária. $\mathrm{O}$ simples fato de um autor tratar de temas regionais e utilizar uma linguagem regional não é suficiente para ele ser considerado regionalista. É necessário que o seu discurso, conforme Stüben (2013, p. 59), comprometa-se em propagar "a cultura de uma região como programa e paradigma", que lhe imponha "limites em relação a outros espaços" ou a defenda "contra um centro".

Nessa perspectiva, Josué Guimarães não pode mesmo ser considerado regionalista, apesar de grande parte da sua obra tratar de temas regionais. Faltam-lhe a visão idílica, o tom laudatório e a ação conivente com a ideologia regional. Ao mesmo tempo, ele não é um autor universalista, porque o universal, de acordo com Renato Ortiz (2007, p. 8), "termina onde começam a cultura e a língua". Logo, a questão da representação da região em Josué deve 
seguir por outro caminho, que de fato contemple as regionalidades como elementos importantes para a construção da sua obra, sem a necessidade de tentar salvaguardá-lo de um epíteto regionalista, com o uso de outro que já se encontra esvaziado. Ler as regionalidades presentes na obra é uma forma de valorizá-la, visto que o autor tinha como bandeira a fidelidade às suas raízes e à sua terra (GUIMARÃES, 1988, p. 3) e foi protagonista de um momento histórico-político que marcou profundamente a vida do estado e da nação: "Quanto ao caudilhismo típico do Rio Grande, confesso que me marcou. Quando criança, em Rosário do Sul, fui testemunha ocular de crimes e atrocidades" (GUIMARÃES, 1988, p. 5).

Essas regionalidades, entendidas como "as relações do fato literário com uma dada região" (POZENATO, 2003, p. 155), são facilmente perceptíveis e, portanto, passíveis de análise em uma obra como A ferro e fogo. Isso tem a ver com a preocupação do escritor em privilegiar temas relacionados ao universo de sua região (de origem ou não), em geral atrelados a fenômenos históricos que de alguma forma passam pela representação de elementos políticos, sociais e culturais.

Em A ferro e fogo, particularmente no primeiro volume, Tempo de solidão, Josué Guimarães parte da saga de uma família de imigrantes alemães para ir muito além do que apenas contar na ficção a história da imigração, no Rio Grande do Sul, no século XIX. Embora os alemães sejam os protagonistas da narrativa, lutando cada um a seu modo para sobreviver e vencer em um novo ambiente, notadamente hostil e, por que não dizer, selvagem, a região consiste em um meio fundamental para a caracterização do sujeito regional. É essa região, observada a partir de uma perspectiva simbólica, não geográfica, que fará com que homens e mulheres adaptem seus hábitos europeus a novos padrões de comportamento sulamericanos. No sentido contrário, os integrantes desse grupo, com o passar do tempo, levam a região a ser reconhecida como tal justamente por causa das regionalidades identificadas com o fenômeno da imigração.

Narrar os primeiros momentos da imigração alemã no Sul do Brasil significa, no plano das regionalidades, lidar com a própria formação do Rio Grande do Sul, ainda incipiente sob todos os pontos de vista, seja econômico, social ou político. Em outras palavras, a região hoje facilmente reconhecida pelas suas peculiaridades culturais, e que de regra transborda as fronteiras demarcadas por rios e outros aspectos geográficos, em meados do século XIX ainda estava em processo de constituição. Evidentemente esse processo segue um fluxo contínuo que nunca se encerra, mas o que importa neste momento é destacar que o espaço regional onde transcorrem os eventos de A ferro e fogo caracteriza-se por ser uma "terra de ninguém", 
conforme a definição do narrador ao se referir à luta pelo controle da região entre castelhanos e brasileiros (GUIMARÃES, 1973, p. 46).

Nesse ambiente de "disputas" pelo domínio de um grupo sobre outro, que também inclui brasileiros contra alemães, alemães contra alemães e brasileiros contra brasileiros (incluindo os escravos), as regionalidades assumem uma conotação de legitimação como em raras ocasiões na ficção sul-rio-grandense. Diferentemente do que ocorre em $O$ continente, primeira parte da trilogia $O$ tempo e o vento, de Erico Verissimo, em que o habitante sul-riograndense está no centro da representação, em A ferro e fogo esse papel cabe ao imigrante alemão. No primeiro caso, o elemento estrangeiro surge sob o olhar de um narrador identificado com o nativo; no segundo, o ponto de vista inverte-se para revelar a posição do estranho em novas terras. Assim, a perspectiva romanesca de Josué Guimarães permite o descortinar em grande escala das peculiaridades de um grupo social que passa a integrar o tecido social regional. Esse processo implica não apenas a aculturação do "forasteiro", já habituado ao chimarrão e à cachaça, como demonstram os costumes de Daniel Abrahão, mas também na incorporação de práticas desse sujeito pelo nativo. O caldo disso tudo, ao fim e ao cabo, definirá no plano simbólico a região reconhecida como a dos "gaúchos", não necessariamente aquela habitada por homens valentes vestidos de bombacha, como a literatura regionalista - aquela caracterizada pela exaltação do tipo gaúcho - tratou de difundir.

Apesar de a simples referência à palavra regional(ismo) incomodar escritores cuja obra gira em torno de uma temática identificada com uma determinada região, entre eles Josué Guimarães, não há como negar a existência de uma "consciência regional" por parte desses escritores. Essa "consciência regional” leva a um discurso literário que, na acepção de Stüben $(2013$, p. 40), debate "o que deve ser reconhecido como específico de uma região e seu 'caráter'”. Dessa forma, as características de uma região são representadas na literatura e, a posteriori, essa representação atua sobre os leitores de forma a estabelecer uma imagem dessa mesma região. O resultante disso seria o que Stüben chama de "literarização da região e regionalização da literatura", dois movimentos que se entrecruzam constantemente, até se tornarem indissolúveis.

Em A ferro e fogo, o fato de Catarina e Daniel Abrahão terem se estabelecido em uma localidade remota ao Sul da província - independentemente de terem sido enganados por Gründling —, e não em uma das colônias alemãs próximas a Porto Alegre, já indica uma disposição do romancista para ampliar o espaço regional representado. Em meio a uma guerra que contrapõe inimigos históricos, o casal de imigrantes precisa lidar com ambos os lados 
para sobreviver. Catarina expõe-se ao perigo e aceita a violência sexual, na medida em que essa postura consiste na única saída para salvar a família; Daniel, por sua vez, prefere viver em um buraco para não encarar a luta. Para ele, o que no início era um recurso emergencial para escapar da morte acaba tornando-se um recurso duradouro para evitar a vida. Por conseguinte, Catarina tem a força necessária para fazer a família Schneider prosperar nos negócios. Daniel, por outro lado, deixa-se levar pelas decisões da esposa. Essa inversão de papéis na figura da liderança familiar, ao modo de Ana Terra e Bibiana, as personagens femininas mais marcantes de Erico Verissimo, indica logo nas primeiras páginas que $A$ ferro $e$ fogo não tem nada de regionalista. Da mesma maneira que Erico, Josué Guimarães também atribui à mulher outros valores, além de servir ao homem e cuidar da educação dos filhos. Esse comportamento feminino, digamos, "superior", que se opõe ao modelo da submissão, constitui uma regionalidade propagada pela literatura sobre a região sul-rio-grandense e, de alguma forma, passou a ocupar um lugar no imaginário coletivo.

A luta de Catarina e Daniel Abrahão pela adaptação nessa paisagem hostil inclui domar a natureza, comandar o trabalho dos negros, aceitar o apoio de um índio (Juanito) e aprender a língua nativa. Se na colônia o imigrante poderia passar muitos anos sem precisar falar português, como de fato registra a história da imigração, ele não teria a mesma facilidade em uma região inóspita, lugar de passagem para soldados brasileiros e castelhanos. A língua, nesse contexto, torna-se condição essencial de integração social. Por isso, assim como o uso de uma linguagem regional (por exemplo, a "gaúcha") não significa necessariamente que a obra seja regionalista, o mesmo vale para a língua alemã. A despeito de, na narrativa, as frases e interjeições em alemão escassearem à medida que as personagens integram-se ao contexto social, as interferências em língua alemã no romance são frequentes.

Em um plano simbólico, a representação do idioma dos imigrantes tem implicações importantes no que tange às regionalidades da região. Primeiramente porque, por uma questão de proximidade geográfica, o português recebeu muitas influências do espanhol falado no Uruguai e na Argentina, e nada mais natural que a literatura tenha se apropriado desse aspecto como matéria para a ficção. No caso da língua alemã, além de não haver proximidade entre os grupos sociais, também há um distanciamento em relação aos códigos linguísticos. Ou seja, português e alemão pertencem a matrizes linguísticas distintas, românica e germânica, mas isso não impede a ocorrência de apropriações de um lado e de outro. Ao mesmo tempo em que o "teuto-gaúcho" desenvolveu uma linguagem dialetal híbrida, resultado do cruzamento de um dos tantos dialetos germânicos falados na Europa do século XIX com o português do Brasil, a literatura tratou de incorporar o modo alemão de se expressar ao falar "brasileiro". 
Essas relações lexicais, como marcas de regionalidade, incluindo também o italiano e o polonês, entre outros, fazem com que a imagem de um gaúcho de fala monolítica sofra profundas interferências. Esse caso específico da linguagem revela o quanto a representação de um jeito de falar pode estar distante do regionalismo do tipo laudatório. Em A ferro e fogo, frases como "- Unglaublich, mas sinto vontade de tomar um mate. A gente se acostuma a tudo" (GUIMARÃES, 1973, p. 43, grifo do autor) sinalizam o intercâmbio linguístico e cultural em fase de passagem. A região atua sobre Daniel Abrahão nos costumes e na língua, da mesma maneira que ele vai atuar sobre a região, ao seu modo, quando sair do buraco em que se esconde e começar a produzir carroças e serigotes com "marca alemã".

Por sinal, a perseverança para o trabalho, tema caro ao discurso histórico regionalista em relação aos imigrantes, também se faz presente em A ferro e fogo. Evidentemente a narrativa de Josué Guimarães vai por um caminho diferente daquele que coloca o imigrante — em geral o italiano e o alemão - como sujeito portador de qualidades congênitas para o trabalho, um posicionamento ideológico que tem a ver com uma suposta supremacia racial e foi apropriado pela literatura como propaganda política institucionalizada por partidos e órgãos públicos. Na ficção, a família Schneider alcança a prosperidade nos negócios graças a toda uma conjuntura favorável, que inclui a proximidade com Porto Alegre, a carência de produtos essenciais na região, o conhecimento prévio de técnicas agrícolas e industriais (ainda que rudimentares), o acesso a meios de produção até então negados aos nativos, a mão de obra desse nativos e, não menos importante, o desejo de vingança de Catarina contra Gründling. Para garantir o sustento da família, a matriarca usa como combustível a ideia fixa de prejudicar economicamente o homem que os enviou para uma região conflagrada a fim de servirem ao contrabando de armas, sem que soubessem disso.

Essas e outras situações da trama demonstram que A ferro e fogo passa ao largo de uma "ideologia do trabalho" no meio colonial, segundo a qual a industrialização sul-riograndense surge do nada, graças unicamente ao sacrifício pelo trabalho e à capacidade superior do imigrante. Muito pelo contrário, essa indústria incipiente emerge justamente das rivalidades dentro da colônia, "quando os colonos começavam a brigar entre si por causa de cercas mal colocadas" (GUIMARÃES, 1973, p. 206), aproveitando-se de condições especiais que beneficiaram o elemento estrangeiro em um meio regido pelo sistema escravocrata. De toda forma, não custa acentuar que, também na temática do trabalho, Josué Guimarães mostra-se atento às questões regionais, procurando a verossimilhança, sem cair na ingenuidade do discurso regionalista. 
Por fim, e com o perdão da ousadia, Josué Guimarães erra o alvo quando tenta reduzir a paisagem a um mero "acabamento à pintura" dentro de sua obra, na medida em que não podem haver conflitos e contradições do homem sem uma "paisagem". Tanto o enfoque temático - regional — quanto os elementos paisagísticos e linguísticos estão intrinsecamente ligados à representação da região na narrativa de $A$ ferro e fogo, sem que esses componentes soem com alguma nota de vibração laudatória. No plano da fabulação, não há problema que detalhes paisagísticos venham à tona para situar as personagens no meio, desde que isso não ocorra de forma a enaltecer essa paisagem em relação a outra. Isso pode ser observado no seguinte trecho:

Schneider fazia incursões mais distantes em busca de perdizes e de marrecões: sabia como apanhar capivara num banhadão a cerca de duas léguas: aprendera a evaporar água do mar, trazida em pipas, para com o sal preparar o charque. Já colhia mandioca, batata e cebola, que a terra solta era especial para isso; a mesa começara a ficar mais farta e variada. (GUIMARÃES, 1973, p. 32, grifo nosso).

A paisagem que envolve a família Schneider constitui-se de caminhos difíceis, picadas e banhados, e abriga os mais diversos exemplares da fauna local. Esse novo universo, que não deixa de ser exótico, tem um efeito mágico diante dos olhos dos imigrantes. A natureza é diversa e capaz de causar encantamento em um menino como Philipp, que descobre "os arredores, o olho-d'água, o banhado raso, os sapos verdes de olhos parados, o papo inchando e desinchando" (GUIMARÃES, 1973, p. 25). Daniel Abrahão, por sua vez, precisa tirar da terra o sustento do grupo. Dessa forma, a paisagem da região influencia sobremaneira os destinos do homem, seja no âmbito prático da luta pela sobrevivência, seja no âmbito da simples contemplação.

Pelo exposto, compreende-se que Josué Guimarães não queria se considerar um escritor regional, na medida em que o regional(ismo) está tradicionalmente associado à literatura de qualidade duvidosa - e nenhum escritor deseja que o valor de sua obra seja questionado. No entanto, o que se discute não são as limitações ou as virtudes do escritor, tanto do ponto de vista da recepção ou difusão quanto da qualidade estética. Ao analisar as representações de regionalidade, busca-se conhecer as peculiaridades que fazem com que o leitor reconheça na obra uma determinada região.

Em A ferro e fogo, as regionalidades revelam inúmeros aspectos de um grupo social — os imigrantes alemães — no momento de sua inserção em uma região ainda desconhecida. Os conflitos gerados a partir dessa relação falam da natureza humana em uma perspectiva ampla — se preferirem, "universal" —, mas sem que isso signifique um apagamento do ser regional. Assim, ao lermos um romance como A ferro e fogo pelo viés de suas regionalidades, podemos pensar sobre o "regional" sem receio de cair em qualquer tipo de juízo de valor. 
Afinal, se a ideia de universal termina onde começam a língua e a cultura (ORTIZ, 2007), a ideia do regional começa onde terminam as barreiras que impedem sua análise em aportes teóricos cujas formulações não contrapõem o local ao universal.

\section{Referências}

ATLAS das representações literárias de regiões brasileiras / IBGE. V.1., Coordenação de Geografia, Rio de Janeiro: IBGE, 2006.

BARBIERI, Therezinha. Colonização a ferro e fogo. In: REMÉDIOS, Maria Luíza Ritzel (Org.). Josué Guimarães: o autor e sua ficção. Porto Alegre: Ed. da Universidade/UFRGS; Edipucrs, 1997. p. 27-37.

BARCIA, Pedro Luis. Hacia un concepto de la literatura regional. In: RIVEIRO, Gloria Videla; CASTELLINO, Marta Elena. Literatura de las regiones argentinas. Mendoza: Universidad Nacional de Cuyuo, 2004. p. 25-45.

BOSI, Alfredo. História concisa da literatura brasileira. 2. ed. São Paulo: Cultrix, 1972.

CHIAPPINI, Lígia. Do beco ao belo: dez teses sobre o regionalismo na literatura. Estudos históricos, Rio de Janeiro, v. 8, n. 15, p. 153-159, 1995.

GUIMARÃES, Josué. A ferro e fogo: tempo de solidão. 2. ed. Rio de Janeiro: José Olympio, 1973.

JOSUÉ Guimarães. 3.ed. Porto Alegre: IEL, AGE/ULBRA, 1988.

ORTIZ, Renato. Anotações sobre o universal e a diversidade. Revista Brasileira de Educação, v. 12, n. 34, jan./abr. 2007.

PELINSER, André Tessaro. Guimarães Rosa e seus precursores: regionalismo, deslocamentos e ressignificações. 2015. 349 f. Tese (Doutorado em Estudos Literários) Universidade Federal de Minas Gerais (UFMG), 2015.

POZENATO, José Clemente. Processos culturais: reflexões sobre a dinâmica cultural. Caxias do Sul: Educs, 2003.

RETTENMAIER, Miguel. Pesquisa literária e acervo: a maldição dos manuscritos, Desenredo, v. 4, n. 2, p.137-145, jul./dez. 2008.

STÜBEN, Jens. Literatura regional e literatura na região. In: ARENDT, João Claudio; NEUMANN, Gerson Roberto (Org.). Regionalismus - regionalismos: subsídios para um novo debate. Caxias do Sul: Educs, 2013. p. 37-73.

VERISSIMO, Erico. A liberdade de escrever: entrevistas sobre literatura e política. Apresentação de Luis Fernando Verissimo; organização de Maria da Glória Bordini. São Paulo: Globo, 1999. 